\title{
Synthesis, molecular modeling and evaluation of anticancer activities of some 1-substituted-4-phenyl piperazine derivatives
}

\author{
Mehmet Abdullah Alagöz ${ }^{1}$, Zeynep Özdemir ${ }^{1}$, Ceylan Hepokur ${ }^{2}$, H. Eren Bostanc1 ${ }^{2}$, \\ Tijen Önkol ${ }^{3 *}$ \\ ${ }^{I}$ Inönü University, Faculty of Pharmacy, Department of Pharmaceutical Chemistry, 44210 Malatya, Turkey \\ ${ }^{2}$ Cumhuriyet University, Faculty of Pharmacy, Department of Biochemistry, 058140 Sivas, Turkey \\ ${ }^{3}$ Gazi University, Faculty of Pharmacy, Department of Pharmaceutical Chemistry, 06330 Ankara, Turkey
}

\section{Introduction}

Cancer is a disease caused by the disruption of the cell cycle, which is controlled by the cell's genetic material. Chemotherapy, radiotherapy and surgical methods are used as standard in cancer treatment. In chemotherapy, tumor cells are targeted to destroy or stop their growth. Due to the fact that the existing anticancer drugs do not have sufficient effect and they have various side effects, new anticancer drugs are needed to be developed (Herrero and Medarde, 2015; Zhang et al., 2014). In this study, three new 1-substituted-4-phenylpiperazine derivatives, which are expected to have anticancer activity, were designed, synthesized and anticancer activities were investigated.

\section{Materials and methods}

\section{Molecular modeling studies}

Maestro 11.8 (Schrödinger, LLC, NY) program was used in molecular modeling studies. Threedimensional structures of compounds were constituted with Maestro11.8 software with the aid of MacroModel software and the OPLS_2005 force field parameters, and were optimized by conjugated gradient method. The structure of HSP90 protein (PDB ID: 1YET) retrieved from RCSB (www.rcsb.org) for C6 and MCF-7 (Dogan et al., 2017).

\section{Chemistry}

Synthesis of compounds begins with 2acetylnaphthalene. 1- (Naphthalen-2-yl) -2bromoethanone is obtained as a result of the bromination reaction (Immediata and Day, 1940). Compounds 1a, 1b and 1c were synthesized by reaction of this compound with 1-phenylpiperazine, 1- (3- (trifluoromethyl) phenyl) piperazine and 1- (2methoxyphenyl) piperazine, respectively (Ozdemir et al., 2015). The structures of the obtained compounds were illuminated by spectral methods ( $\left.{ }^{1} \mathrm{H}-\mathrm{NMR},{ }^{13} \mathrm{C}-\mathrm{NMR}, \mathrm{IR}\right)$.

\section{Activity studies}

MCF-7 (breast cancer cell line), C6 (rat brain glioma adenocarcinoma cell line) and WI-38 (healthy human fibroblast cell line) were used in activity studies. In these studies, 5-fluorouracil (5FU), an anticancer drug, was used as the reference compound. The $\mathrm{IC}_{50}$ value of 3 synthesized

\footnotetext{
* tijen@gazi.edu.tr
} 
compounds and 5-FU was determined by XTT (Chiang et al., 2006).

\section{Results and discussion}

The interactions of the compounds with residues in the active region of the HSP90 protein were examined and docking scores were calculated. The compound with the best docking score is $1 \mathrm{c}$. In the study, the 1c was observed to be more active in the C6 cell line than 5-FU; $1 \mathrm{~b}$ in MCF-7 cell line was found to have an activity close to 5-FU.

It was determined that the docking scores obtained from molecular modeling studies are in harmony with the activity studies.

\section{Conclusion}

In this study, it was determined that the molecules synthesized according to the results obtained from molecular modeling studies have significant anticancer activity. It also has low cytotoxic effects against healthy cells. Due to these high effects and properties, these molecules become potential anticancer drug candidates. Advanced in vitro and in vivo preclinical and clinical studies are needed for compounds to become candidates for anticancer drugs.

\section{References}

Chiang, L., Ng, L.T., Linc, I., Kuod, P., Linc, C., 2006. Anti-proliferative effect of apigenin and its apoptotic induction in human Hep G2 cells. Cancer Lett. 237, 207-214.

Doğan, I.S., Saraç, S., Sari, S., Kart, D., Gökhan, Ş., Vural, I., Dalkara, S., 2017. New azole derivatives showing antimicrobial effects and their mechanism of antifungal activity by molecular modeling studies. Eur. Med. Chem. 130, 124-138.

Herrero, P.E., Medarde, F.A., 2015. Advanced targeted therapies in cancer: drug nanocarriers, the future of chemotherapy. Eur. J. Pharm. Biopharm. 93, 52-79.

Immediata, T., Day A.R., 1940. Beta-naphtyl derivatives of ethanolamine and nsubstituted ethanolamines. J. Org. Chem. 5, 512-527.

Ozdemir, Z., Karakurt, A., Calis, U., Günal, S., Light, S., Sahin, S.Z., Dalkara, S., 2015. Synthesis, anticonvulsant and antimicrobial activities of some new [1-(2Naphthyl)-2- (pyrazol-1-yl) ethanone] oxime ethers. Med. Chem. 9, 41-49.

Zhang, L., Peng, X.M., Damu, G.L., Geng, R.X., Zhou, C.H., 2014. Comprehensive review in current developments of imidazole-based medicinal chemistry. Med. Res. Rev. 34, 340-437. 